\title{
O GRUPO DE PESQUISA CULTURA, AMBIENTE E EDUCAÇÃO: APRESENTAÇÃO E REFERÊNCIAS TEÓRICO-METODOLÓGICAS
}

\author{
Isabel Cristina de Moura Carvalho ${ }^{1}$
}

Marcelo Gules Borges ${ }^{2}$

Resumo: $O$ texto articula os atuais referenciais teórico-metodológicos do grupo de pesquisa (GP) Cultura, Ambiente e Educação, existente desde 2005 no diretório de pesquisa do Conselho Nacional de Desenvolvimento Científico e Tecnológico (CNPq). Partindo do pressuposto de que existe em curso um processo de ambientalização das esferas sociais, o GP se propõe a analisar como este configura práticas e experiências que se instituem como um habitus ecológico, particularmente no campo educativo e religioso. Para isso se elegeu uma orientação antropológica a fim de compreender como práticas de Educação Ambiental e práticas religiosas que internalizam uma orientação ecológica produzem no plano individual e institucional experiências associadas à formação de um sujeito virtuoso (sujeito ecológico) ligado às paisagens e aos lugares. Além disso, no plano coletivo, pretendese investigar como essas instituições transformam o campo ambiental e se transformam ao incorporar um idioma ecológico capaz de produzir, entre outras coisas, o deslocamento de uma "cidadania política" em direção a uma "cidadania ambiental".

Palavras-chave: ambientalização social; experiências educativas; cidadania ambiental; habitus ecológico.

Abstract: This text articulates the current theoretical and methodological bases of the Culture, Environment and Education research group, which was created in 2005 in association with the research directory of the National Council for Scientific and Technological Development $(\mathrm{CNPq})$. Assuming that there is an ongoing process of greening of social spheres, the research group analyzes how this sets up practices and experiences that form an ecological habitus, particularly in the educational and religious fields. In order to carry out such analysis, an anthropological approach was adopted to understand how environmental education and religious practices with an implicit ecological view produce, both within the individual and institutional dimensions, virtuous (ecological) subjects

\footnotetext{
${ }^{1}$ Psicóloga, doutora em Educação, professora do PPGEDU/FACED da PUCRS e líder do Grupo de Pesquisa.

2 Biólogo, doutorando em Educação (PUCRS) e membro do Grupo de Pesquisa.
} 
who are connected to landscapes and places. Furthermore, regarding the collective dimension, the research group intends to investigate how those institutions transform themselves and the environmental field by acquiring an ecological language that produces, among other things, the movement from a "political citizenship" toward an "environmental citizenship".

Keywords: greening of social spheres; educational experiences; environmental citizenship; ecological habitus.

\section{Breve Histórico do Grupo de Pesquisa}

O Grupo de Pesquisa (GP) Cultura, Ambiente e Educação existe desde 2005 no Diretório de Pesquisa do Conselho Nacional de Desenvolvimento Científico e Tecnológico $(\mathrm{CNPq})^{3}$. Criado inicialmente na Universidade Luterana do Brasil, RS, reuniu pesquisadores em torno das linhas de pesquisa: Pedagogias Culturais e Educação e Sustentabilidade. Desde março de 2009 o Grupo foi vinculado e certificado pela Pontifícia Universidade Católica do Rio Grande do Sul (PUCRS) acompanhando a mudança institucional da líder do grupo. Em 2010 o grupo foi reorganizado, centrando-se na temática Educação e Antropologia e nas pesquisas que se efetivaram nos últimos anos com a colaboração de alunos e professores do Programa de Pós-Graduação (PPG) em Educação da PUCRS e do PPG em Antropologia da Universidade Federal do Rio Grande do Sul (UFRGS). Esta parceria tem se constituído sobre o pressuposto de que a cultura tem uma dimensão constitutiva na produção dos significados que orientam a vida social e marcam o olhar humano para seu entorno construindo a um só tempo, subjetividade, identidade e objetividade/realidade.

O GP se constitui como uma arena de diálogo e convergência das pesquisas dos seus participantes, focando nestas os modos sociais de perceber e experienciar o ambiente e a atribuição de sentidos prevalentes que formam o que poderíamos chamar, provisoriamente, de uma "cultura ambiental contemporânea”. Para tanto, o GP direciona seus esforços no sentido de buscar conjuntamente a articulação dos campos de saber da educação e da antropologia de modo a identificar processos de produção dos sentidos culturais dos domínios ora englobados no conceito de natureza ora reunidos na idéia mais ampla de ambiente.

Em termos da classificação de áreas do $\mathrm{CNPq}$, da área mais ampla para a mais específica, o GP está vinculado às: Ciências Humanas, Educação e Tópicos Específicos de Educação onde os trabalhos em Educação Ambiental têm sido classificados, uma vez que esta subárea ainda não existe na árvore de subcategorias de educação no CNPq.

\footnotetext{
${ }^{3}$ Disponível em:

http://dgp.cnpq.br/buscaoperacional/detalhegrupo.jsp?grupo=0006708ISZ9KU1
} 


\section{Linhas de Pesquisa do GP}

\section{Linha 1: Ecologia, saúde e religião}

A presente linha de pesquisa (2008-2011) tem como proposta analisar as práticas de aperfeiçoamento de si e do ambiente, voltadas para a saúde e o bem estar físico, mental e espiritual, nas práticas ecológicas em geral e nas práticas de Educação Ambiental em particular. O principal objetivo é investigar nos casos estudados a expectativa de cura e bem estar individual e planetário como experiências formativas associadas à formação de um sujeito (self) virtuoso, sintonizado com os ideais de bem viver ecológico (sujeito ecológico). Para tanto o foco do estudo é dirigido para práticas ecológicas que operam certa "sacralização" da natureza bem como para práticas religiosas que operam uma "naturalização" do sagrado. É utilizado o método etnográfico para compreender nos casos estudados as experiências dos praticantes. Pretendemos discutir os possíveis pontos de convergência nos sentidos de natureza, do sagrado e de saúde nestas práticas ecológicas que permita acessar a relação existencial dos pratican-tes com as paisagens e os lugares onde estas práticas ocorrem. A hipótese teórica que nos guia é baseada em Merleau-Ponty e se apóia na idéia de que a paisagem, enquanto "corpo do mundo", pode ser tomada como o solo da cultura, no sentido de que o sujeito humano, em sua condição corporal de "ser no mundo", está não apenas implicado na paisagem, mas esta é a condição de seu engajamento no mundo e na cultura.

\section{Linha 2. Ambientalização das questões sociais}

Esta linha (2010-2013) visa analisar e compreender os processos de ambientalização da sociedade brasileira na área da educação, focalizando particularmente a Educação Ambiental. Entendemos por ambientalização o processo de internalização da questão ambiental nas esferas sociais e na formação moral e dos indivíduos. Este processo tem sido identificado tanto na emergência de questões e práticas ambientais como um fenômeno novo quanto na reconfiguração de práticas e lutas tradicionais que se transformam ao incorporar aspectos ambientais. Ainda, como objeto desta pesquisa, destacamos a hipótese do deslocamento de uma "cidadania política", que foi a base para a emergência da democracia e da educação para a democracia (Dewey) na passagem do século XIX para o século XX, em direção a uma "cidadania ambiental" globalizada e inclusiva do ambiente como "sujeito" de direitos, como um traço histórico da passagem do século XX para o século XXI. O método de pesquisa está centrado na etnografia e na observação-participante de práticas educativas como recursos para compreender a instituição de um habitus (Bourdieu, 1998) ou ainda de um idioma ecológico na sociedade (Comaroff e Comaroff, 2001). Ao mesmo tempo, procura apontar para o caminho inverso, das transformações que vem ocorrendo na própria noção e no significado do que seja ambiental a partir da sua incorporação no âmbito das instituições educacionais. Por fim, o projeto busca estabelecer um diálogo interdisciplinar 
entre educação e antropologia, contribuindo para a formação de uma antropologia da educação.

\section{Linha 3: A produção Científica em Educação Ambiental (2003-2012)}

Esta linha investiga a constituição de um campo de produção científica em educação ambiental e analisa parte desta produção a partir dos trabalhos apresentados em três principais eventos científicos de âmbito nacional da área: as Reuniões Anuais da Associação Nacional de Pós-Graduação e Pesquisa em Educação (ANPEd); os Encontros da Associação Nacional de Pós-Graduação e Pesquisa em Ambiente e Socie-dade (ANPPAS) e os Encontros de Pesquisa em Educação Ambiental (EPEA). A metodologia integra a estruturação e atualização de um banco dados e o acompanhamento da produção científica da área por meio de análises quantitativas e qualitativas. A análise visa o aprimoramento das categorias analíticas e a elaboração de estudos temáticos e regionais, no sentido de melhor compreender as particularidades desta produção.

\section{Referenciais teóricos e metodológicos que têm orientado as pesquisas}

A ambientalização das práticas sociais está produzindo reformulações teóricas no campo da antropologia e da educação. Nesse sentido, para nós é importante manter e aprofundar a interlocução com os autores que trabalham com a perspectiva fenomenológica, a antropologia fenomenológica e com a antropologia ecológica. Identificamos em Merleau-Ponty, Csordas e Ingold respectivamente, contribuições que nos ajudam a relativizar a dicotomia natureza/cultura e imaginar as possibilidades de um caminho teórico que, em artigos decorrentes da pesquisa anterior, temos chamado de epistemologias ecológicas (Carvalho e Steil, 2008; 2009; 2010).

A teoria da prática de Bourdieu também tem sido uma importante referência teórico-metodológico nesta proposta investigativa. A associação entre Bourdieu e a perspectiva fenomenológica não é nova e já foi explorada por outros autores como na proposição do paradigma da corporeidade de Csordas (2008). Para compreensão dos processos de internalização da questão ambiental os conceitos de campo social e de habitus (Bourdieu, 1977, 1989) são particularmente adequados, pois nos permitem identificar ao mesmo tempo os rebatimentos institucionais e coletivos quanto os efeitos individuais sobre valores, atitudes e comportamentos. Neste sentido temos observado a formação de um habitus ecológico.

Além da aplicação da noção de habitus para o campo ambiental, temos buscado também pensar as relações com o ambiente em termos de uma antropologia da paisagem. Neste sentido, propomos a transposição da noção de corpo como "local da cultura" (Cordas, 2008) para a de paisagem. Esta proposição se sustenta no deslocamento que o próprio Merleau-Ponty faz em seu livro O visivel e o invisivel (Merleau-Ponty, 2000) ao introduzir a noção de "carne", como corpo do mundo. $\mathrm{Na}$ mesma direção, incorporamos as 
contribuições de uma antropologia da paisagem (Anthropology of Landscape) em que as noções de espaços incorporados (embodied spaces, Low e Lawrence-Zuniga, 2006) ou paisagens incorporadas (embodied landscapes, Ingold, 2000) são centrais para se repensar a relação natureza e cultura.

$\mathrm{Na}$ presente proposta de pesquisa do GP, retomamos as preocupações acima a luz de dois novos campos argumentativos: i) da sociologia da educação, com ênfase na contribuição de Durkheim e Dewey que destacam o papel da educação como formação moral na sociedade secular; ii) da antropologia que discute as relações entre o local e o global no fenômeno ambiental, tendo em vista a formação de um idioma ecológico na tradução de questões sociais e políticas. A seguir desenvolvemos brevemente cada um destes campos argumentativos.

\section{Educação moral e cidadania}

A educação como via régia da formação de um sujeito socialmente responsável e cidadão de direitos e deveres é postulada por vários autores do pensamento social na modernidade. De Rousseau, no século XVIII, a Durkheim e Dewey, no final do século XIX e primeira metade do XX, há uma linha de continuidade que atribui à educação o papel de reprodução da vida social. Sobretudo em Durkheim e Dewey encontramos as bases filosóficas de uma moral secular e racional que busca garantir o vínculo social frente aos desafios antepostos pelas transformações produzidas pelo avanço da técnica, da industrialização e da urbanização. A crise da autoridade da religião, enquanto instituição garantidora do laço social e a emergência da ciência e da democracia como novo paradigma para a cidadania constituem o horizonte de preocupação destes dois pensadores. Em contextos diferentes - Dewey no da democracia liberal nos Estados Unidos e Durkheim no do republicanismo francês - ambos buscam na razão e no método científico experimental uma base de autoridade capaz de substituir a função até então exercida pela religião de manter coesa a sociedade plural.

Neste contexto, a educação entendida como mecanismo imprescindível de transmissão cultural e societária. Como afirma Dewey, "a sociedade existe por meio de um processo de transmissão semelhante ao da vida biológica. Esta transmissão ocorre por meio da comunicação de hábitos, fazeres, pensamentos e sentimentos da geração mais velha para a mais jovem" (1997, p. 3). Do mesmo modo, Durkheim afirma que: "toda prática educacional, qualquer que seja, tem em comum uma característica essencial: todas elas partem de uma influência exercida por uma geração sobre a geração seguinte com o intuito de adaptar esta última ao meio social no qual ela é chamada a viver" (1977, p. 95). Neste sentido, ambos compreendem a educação como uma "instituição genuinamente sociológica, capaz de prover o contexto no qual os padrões normativos do pensamento, do comportamento e da interação social podem ser aprendidos em comunidade" (DILL, 2007, p. 223).

Diante do enfraquecimento e declínio das instituições religiosas e do conseqüente pluralismo moral que marca a sociedade moderna, Durkheim e 
Dewey, imbuídos de um projeto político libertador, buscam transferir para a educação o princípio de autoridade que a religião exercia até então. Tratava-se, como nos lembra McClustkey (1958), em sua interpretação do pensamento destes autores, de libertar o ser humano do cancro do dogma. No entanto, se ambos os autores coincidem em estabelecer um princípio de autoridade fundado sobre o método racional e científico a ser transmitido de geração para geração por meio da educação, eles divergem em termos da sua fonte. Enquanto para Durkheim, a fonte se encontra na sociedade, como uma autoridade externa aos indivíduos; para Dewey, ela está na experiência dos indivíduos. Assim, se Durkheim funda a validade do ato moral na consciência coletiva, estabelecendo uma correspondência direta entre os conceitos simbólicos do pensamento e as categorias coletivas, advindas da organização social; Dewey interpõe, entre o indivíduo e a sociedade, a consciência individual, como a instância onde a validade do ato moral é testada e descoberta por meio da experiência. Portanto, a natureza desta autoridade e o modo como ela é criada e mantida representam o divisor de águas entre estes dois teóricos da moralidade secular e racional do século XX.

Para Dewey, pensador emblemático 4 do pragmatismo progressista nos EUA, a democracia era tomada como a mais alta realização humana para a qual se exigia um sujeito cooperativo, solidário, comunitário e altruísta. A formação deste sujeito ideal, cujo modo de vida seria pautado pelo pensamento racional e cientifico, tornaria possível a felicidade humana e o progresso social. A missão da educação seria a de combater o individualismo hobbesiano, isto é, a natureza selvagem e competitiva que estaria na base da desordem moral dos processos de urbanização e industrialização. Desta forma, a escola, enquanto instrumento privilegiado da educação humana assume um papel central na formação moral para a democracia em vista da constituição e consolidação do Estado de Bem Estar Social (welfare state).

Esta missão civilizatória e progressista da educação, como bem demonstra Popkewitz (2008, 2005), esteve fortemente ligado à Reforma Protestante e aos conceitos de salvação puritana que encontraram nos ideais políticos da democracia e na valorização da ciência um novo idioma. A "Sublime tecnologia" encarnava a apoteose da razão e seu rebatimento na educação foi a incorporação de uma idéia de ciência como modo de ordenação da vida individual e do planejamento da sociedade na reforma pedagógica.

Interessa-nos, desde as contribuições de Durkheim e de Dewey, explorar o contraste das teses do racionalismo francês e da perspectiva cultural do pragmatismo progressista norte-americano com aquelas de uma Educação Ambiental, produzida a partir das condições históricas da virada do século XX para o XXI. As condições contextuais que tornam a Educação Ambiental

${ }^{4}$ Popkewitz (2008) toma Dewey como personagem-conceito ou pessoa-conceito que conferiu inteligibilidade ao pragmatismo progressista através de uma grade de práticas sociais e culturais. 
razoável e inteligível como discurso moral hoje são muito diferentes daquelas da educação democrática do século XIX. A convicção de Durkheim e de Dewey na educação racional como instância moral contrasta hoje com a crise de fé no método racional e na autoridade moral da sociedade, pondo em xeque o papel da educação na coesão social. Se naquela época estava em jogo à consolidação do Estado Nação, hoje temos a crise deste dispositivo geopolítico e a emergência dos novos desafios de uma sociedade globalizada. No debate ecológico - que é particularmente representativo destas novas configurações contemporâneas - a aposta pedagógica numa educação para a "cidadania ambiental" transcende as fronteiras nacionais e incorpora as questões morais dentro de um quadro planetário.

\section{Global e Local na constituição de práticas ecológicas.}

$\mathrm{Na}$ compreensão dos sentidos acionados no adjetivo "ecológico", cabe destacar o imbricamento entre o local e o global, de modo a questionar uma visão bastante disseminada da força homogeneizadora dos processos globais e da passividade das culturas locais diante desta força. Afirmar uma hipotética sujeição das culturas locais aos discursos universalizantes sobre o ambiente seria o mesmo que desconsiderar sua autonomia e intencionalidade histórica e desconsiderar a potencialidade do local na conformação dos processos globais.

A propósito das reflexões acerca da tensão entre o local e o global na constituição de práticas singulares, destacamos a contribuição de Marshall Sahlins (1997a, 1997b). Tomando como ponto de partida a inexorabilidade da noção de cultura enquanto objeto privilegiado da antropologia, Sahlins contrapõe aos paradigmas que aderem a certo "pessimismo sentimental", que tendem a conferir à globalização capitalista o poder de dissolver diversidade das culturas numa única "aldeia global", onde a singularidade e a criatividade locais nada mais seriam do que "versões locais da civilização Ocidental" (Sahlins, 1997a: 42). Desde esta perspectiva, a expansão do capitalismo desencadearia um processo de desculturação das populações locais que se tenderiam a desaparecer sob a força avassaladora dos processos hegemônicos globais.

$\mathrm{Na}$ contramão desta perspectiva, respaldado por um grande número de exemplos etnográficos de diversas regiões do planeta, Sahlins contradiz esta hipótese do desaparecimento e da assimilação das culturas locais por uma hipotética cultura global. Estas etnografias, longe de evidenciarem a presença de um sistema mundial monológico e determinista, tornam patente a capacidade das culturas locais em manipularem e agenciarem, a partir de sua própria lógica e dinâmica, os elementos culturais exteriores e diversos de sua tradição que a globalização lhes torna acessíveis. Esta visão do processo de globalização desde a experiência local é o que permite perceber o papel ativo e contra-hegemônico das populações periféricas e de grupos vulneráveis, o qual Sahlins chamou de "indigeneização da modernidade", em contraposição ao conceito de globalização. 
Este giro interpretativo da globalização para a indigeneização, proposto por Sahlins, é uma das balizas teóricas que norteia nossa percepção e análise dos processos pelos quais a questão ambiental é incorporada na experiência coletiva de grupos e movimentos sociais e na formação de sujeitos ecologicamente orientados. Partindo, portanto, do olhar e da interpretação etnográfica sobre as práticas, as táticas e as estratégias locais de incorporação e institucionalização da questão ambiental nos campos da educação e da religião, esperamos poder compreender as transformações que vem ocorrendo na própria noção do que seja o ambiental. Ou seja, acreditamos que ao se inscrever no sistema de significados, crenças e valores do campo educacional e religioso o ambiental assume características próprias das lógicas e regras destes campos, ao mesmo tempo em que esses são transformados pelo princípio relacional entre integração e diferenciação, exterior e interior, local e global. Assim, na medida em que tomamos como premissa que não há um sentido real ou originários de ambiental, ao qual todos os outros significados se distanciam ou se aproximam, procuramos compreender os seus múltiplos sentidos como parte de um jogo que funciona a partir de um conjunto de relações e agenciamentos locais de questões globais e vice-versa.

Outra contribuição importante para a compreensão dos processos de ambientalização dos campos da educação e da religião é a dos antropólogos sulafricanos Jean e John Comaroff. A idéia de que o ambiental opera como um idioma franco da globalização, em lugar do idioma republicano e democrático que, como vimos, foi central no pensamento e no projeto político de Durkheim e Dewey, será fundamental para compreendermos os usos e as apropriações táticas e estratégicas que as instituições fazem deste idioma em vista de fins próprios, nem sempre ecologicamente orientados.

Num artigo sobre a relação entre uma catástrofe ambiental na África do Sul e a situação do Estado pós-colonial, John e Jean Comaroff (2001) nos oferecem um denso relato etnográfico com dados coletados na imprensa e a mídia que mostra como as questões ambientais podem servir como um idioma para intervir na arena das disputas políticas. O texto narra um incêndio ocorrido aos arredores da Cidade do Cabo, com grandes prejuízos para a fauna e a flora locais. Acompanhando os relatos da mídia sobre o evento, eles mostram que, se num primeiro momento o foco esteve direcionado para as especulações sobre por quem e como o fogo teria sido provocado; após algumas semanas do ocorrido, o debate tomou outra direção. Um aspecto inicialmente marginal da catástrofe - a presença de plantas exóticas de origem estrangeira na floresta que incendiara - passou a merecer todas as atenções. Como escrevem os autores, a opinião pública passou a acreditar que: "fosse qual fosse a causa inicial do incêndio, o fogo atingiu proporções tão calamitosas apenas devido à presença de plantas estrangeiras invasoras que queimam mais e mais facilmente do que a flora nativa" (Comaroff e Comaroff, 2001, pg. 61).

A acusação de que as plantas "exóticas", estrangeiras, tenham sido a causa do incêndio, cristalizou uma série de tensões que estavam latentes no 
contexto pós-colonial da África do Sul. A porosidade das fronteiras que ameaçava a soberania nacional, o pertencimento e a identidade nacionais foram algumas das questões levantadas pelos sul-africanos a propósito do desastre ecológico. Assim, questões referentes à autoctonia, tão caras à política do Estado pós-colonial, emergiram com o evento e foram expressas num "idioma da natureza". Este idioma, como mostra Comaroff e Comaroff (2001), constitui-se num poderoso elemento capaz de aglutinar em torno da natureza questões relativas à política, à educação, à identidade e à religião. Em certo sentido, a possibilidade de a natureza engendrar disputas, conflitos e tensões que estariam seguindo uma dicotomia clássica para antropologia - no pólo da cultura, nos conduz a questionar a segmentarização desses campos que possivelmente estejam bem mais imbricados, produzindo híbridos (LATOUR, 1994).

\section{Os Membros do Grupo de Pesquisa}

Atualmente fazem parte do GP os seguintes professores pesquisadores: Professores pesquisadores: Dra. Isabel Cristina de Moura Carvalho; Dr. Carlos Alberto Steil; Dra. Michele Tomoko Sato; Dra. Carmen Roselaine de Oliveira Farias ; Dra. Gabriela Scotto; Dr. João Rickli ; Dr. Mauro Grün; Dra. Maria Rita Avanzi; Dra. Martha Tristão;

Além dos seguintes orientandos nos diversos níveis de formação (iniciação científica, mestrado, doutorado e pós-doutorado): Carlos Alberto Genz; Cassiano Pamplona Lisboa; Eriberto Nascente Silveira; Marcelo Gules Borges; Stella Maris Nunes Pieve; Luiz Guilherme Mattos Braga; Maria Claudia Quinto; Beatriz Osorio Stumpf; Rodrigo Ferreira Toniol; Maurício Correia Martins; Jorge Amaro de Souza Borges; Chalissa Beatriz Wachholz; Pádula Rita Ferreira; Tatiana Rubim Klein

\section{Referências}

BOURDIEU, Pierre. Outline of a theory of practrice. Cambridge: Cambridge University Press, 1977.

, O Poder simbólico. Lisboa: Difel, 1989.

CARVALHO, Isabel Cristina de Moura; STEIL, Carlos Alberto. A sacralização da natureza e a "naturalização" do sagrado; aportes teóricos para a compreensão dos entrecruzamentos entre saúde, ecologia e espiritualidade. Ambiente \& Sociedade [on line], v. 11, n. 2, 2008, p. 289-305.

O habitus ecológico e a Educação da Percepção: fundamentos antropológicos para a educação ambiental. Educaşão e Realidade. Porto Alegre, v. 34, 2009.

CARVALHO, Isabel Cristina de Moura; STEIL, Carlos Alberto; PASTORI, Érica. O. Educação ambiental no Rincão Gaia: pelas trilhas da saúde e da religiosidade numa paisagem ecológica. Educação, Porto Alegre, v. 33, n. 1, jan./abr. 2010, p. 54-64. 
COMAROFF, Jean; COMAROFF, John. Naturalizando a nação: estrangeiros, apocalipse e o Estado pós-colonial. Horizontes Antropológicos, Porto Alegre, ano 7, n. 15, p. 57-106, jul. 2001.

CSORDAS, Thomas. Corpo/ significado/ cura. Porto Alegre: Ed. da UFRGS, 2008.

DEWEY, John. A concepção democrática da educação. Pretexto Editora, Viseu, 2005.

. Democracy and education. New York, Free Press, 1977.

. The moral principles in education. Carbonade, Sourthern Illinois University Press, 1975.

. Scholl and society. Chicago, University of Chicago Press, 1905.

DILL, Jeffrey. .S. The Challenge of contemporary moral education. Journal of moral education. Vol. 36, n.2, p 221-237, june 2007.

INGOLD, Tim. The perception of the environment. Essays in livelihood, dwelling and skill. London/Nwe York: Routledge, 2000.

LATOUR, Bruno. Jamais fomos modernos. Ensaio de antropologia simétrica. Rio de Janeiro: Ed. 34, 1994.

LOPES, José Sérgio Leite. Sobre os processos de "ambientalização" dos conflitos e sobre dilemas de participação. Horizontes Antropológicos, Porto Alegre, ano 12, n.25, p.31-64, jan/jun. 2006.

LOW, Setha M.; LAWRENCE-ZÚÑIGA, Denise. The anthropology of space and place. Malden/Oxford/Victoria: Blackwell, 2006.

MACCLUSKY, Neil Gerard. Public Schools and moral education. New York: Columbia University Press, 1958.

MERLEAU-PONTY, Maurice. O visivel e o invisivel. 4. ed. São Paulo: Perspectiva, 2000.

POPKEWITZ, Thomas. The University as Prophet, Science as Its Messenger, and Democracy as its Revelation: John Dewey, University of Chicago President William Rainey Harper, and Colonel Francis Parker. Paper presented at conference on "Pragmatism as the Reticle of Modernization: Concepts, Contexts, Critiques", Centro Stefano Franscini, Monte Verità, Ascona, Switzerland, September, 2008.

(Ed.). Inventing the modern self and John Dewey. Modernities and the traveling of pragmatism in education. New York: Palgravemacmillan, 2005.

SHALLINS, Marshall. "O pessimismo sentimental” e a experiência etnográfica: por que a cultura não é um "objeto" em via de extinção (parte I) Mana. Rio de Janeiro, v.3, n.1, p. 41-73, 1997.

. "O pessimismo sentimental" e a experiência etnográfica: por que a cultura não é um "objeto" em via de extinção (parte II) Mana. Rio de Janeiro, v.3, n.2, p. 103-150, 1997.

Artigo recebido em 20/08/2010 - aprovado em 17/12/2010 